This is not the version of record. The full version of Umar, Tariq (2017) Briefing: Defining safety leadership in construction. Proceedings of the Institution of Civil Engineers - Municipal Engineer, 170(1), pp. 3-5. can be found at https://doi.org/10.1680/jmuen.16.00004 


\title{
Defining Safety leadership in Construction
}

\author{
Tariq Umar MSc, \\ College of Engineering; A'Sharqiyah University, Oman
}

\begin{abstract}
:
This briefing explores the tenets of safety leadership within the construction environment. The scope of this briefing aims to define a universal definition of safety leadership with key components through literature review. Without a clear definition towards safety leadership, a misalignment between safety expectations may occur which can create a misappropriation towards safety efforts. This may adversely impact injury rates within the workplace due to ill-conceived safety leadership behaviours. The detailed definition of safety leadership may serve as a foundation for other industries such as mining, manufacturing or petrochemicals.
\end{abstract}

\section{Introduction:}

Safety leadership within itself is a concept that borrows heavily from the leadership framework with specifics being based upon transformational leadership (Mullen and Kelloway, 2009). The challenges within the construction project environment include personal commitment and responsibility towards safety, communication and organisational culture (Hashim and Chileshe, 2012). A well-constructed definition towards safety leadership can enhance consistency and minimise confusion around the topic as well as rooting safety leadership within the leadership literature. Without a clear definition towards safety leadership, a misalignment between safety expectations may occur which can create a misappropriation towards safety efforts. This may adversely impact injury rates within the workplace due to ill-conceived safety leadership behaviours. Neglecting to define safety leadership may contribute to invalid safety leadership efforts which may dissipate the strength of the overall safety on a project or site. This negative impact can be an immediate fiscal downfall but more importantly a moral and ethical dilemma if someone is injured on a worksite.

\section{Safety Leadership}

To set the scene of leadership as it relates to safety, it was detailed from the work of Long (2013) that the board of directors sets the tone of leadership through governance, whilst the chief executive officer (CEO) personalises the message with operational performance and the senior leadership team applies the strategy. This establishes a practical application in defining the behaviours that are evident in successful safety leaders within the construction environment.

The initial investigation of broader leadership studies as it pertains to safety was warranted through the research of Zanko and Dawson (2012). Conclusions from this research detailed that traditional occupational health and safety (OHS) has focused on policies and systems and there is a notable lack of research on OHS safety leadership behaviours. It was reported that OHS leadership is often lumped into the Human Resources (HR) field and further conceptual development is firmly needed. Safety leadership seems to be spoken of in the same breath as general leadership, without taking into account the nuances of safety. 
A recent study into effective safety leadership defined the construct as 'the process of defining the desired state, setting up the team to succeed and engaging in discretionary efforts that drive the safety value' (Cooper, 2015, p.49). The details behind this definition were investigated and traced back to a website of a consulting company that offers services within the field of safety leadership. Their definition of safety leadership was neither research-based nor contextualised for the construction environment. A lack of a clear definition is further reflected through other research by Read et al. (2010). They detailed the importance of safety leadership when engaging the workforce, although no clear definition of what safety leadership means was provided. A national Australian competency framework towards safety leadership was detailed by Biggs, Dingsdag and Roos (2008) who defined a range of safety terms and approaches to safety leadership, however failed to define safety leadership within the framework or as a stand-alone concept. There is a general sense that the definition of safety leadership is implied, innate or linked to broader leadership studies.

In a study undertaken by Lu and Yang (2010), the impact of safety leadership upon safety behaviour was investigated within terminal operations. Safety leadership was defined within three main dimensions which included safety motivation, safety policy and safety concern. It was detailed that safety leadership is a sub-system of organisational leadership, where visible leadership behaviours provide opportunities for safety issues and concerns to be discussed. The findings from Lu and Yang (2010) are based upon specific components of safety leadership being pooled under transformational and transactional leadership. Deeper elements of safety, culture and safety systems appear to be negated when considering the wider construct of safety leadership and its uniqueness from other leadership fields.

Research conducted by $\mathrm{Wu}$, Chen and Li (2008) investigated the impact that safety leadership has upon a company's safety climate and performance. Their definition and construct of safety leadership was established around safety caring, coaching and controlling. The inclusion of coaching has links within the field of relational leadership but was not detailed specifically towards safety. Their operational definition of safety leadership was borrowed from a safety leadership scale assessment, without an explanation of what safety leadership entails. Results from this study detailed that managers who demonstrate safety commitment positively influence safety performance with safety climate being the moderating component.

In a more recent meta-analytic review, safety leadership was explored under the guise of transformational and transactional leadership (Clarke, 2013). Results showed that transactional leadership is important in ensuring compliance with rules and regulations, whilst transformational leadership is associated with encouraging employee participation in safety. These elements were shown to have a mediating effect on safety culture. Further findings outlined suggestions for future theoretical development into the concept of safety leadership in order to explore leadership flexibility and its application within the safety domain.

The view that transactional safety leadership is warranted can be applied with some of the nonnegotiable elements of safety. This pertains to the compliance of minimum standards of work which employees need to adhere to, sometimes colloquially called 'lifesaving rules'. The context 
of transactional safety leadership within the construction industry may raise some challenges due to this approach being a remnant of the less mature environment.

The application of transactional leadership within the construction industry may serve as a continuation of the status quo and a remnant of the less mature environment. This is echoed by the research of O'Dea and Flin (2001) that outlined leaders within the resources sector have a predilection towards directive leadership and even with knowledge of effective leadership behaviours, still choose to be directive. This in turn has an impact on motivating and controlling some of the more crucial aspects of safety. Recently safety leadership has been defined by Daniel (2015) considering following key components as detailed in figure 1.

\begin{tabular}{|c|c|c|}
\hline $\begin{array}{l}\text { Discipline: } \\
\text { - Personal discipline with } \\
\text { safety } \\
\text { - Applying Discipline to } \\
\text { others }\end{array}$ & Safety Leadership Definition & 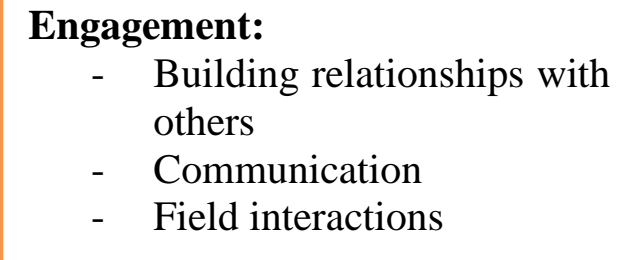 \\
\hline $\begin{array}{l}\text { Values: } \\
\text { - Belief in safety and } \\
\text { importance } \\
\text { - Values of fairness, } \\
\text { integrity } \\
\text { - Sharing values }\end{array}$ & $\begin{array}{l}\text { The demonstration of } \\
\text { safety values through } \\
\text { the creation of a } \\
\text { vision and the } \\
\text { promotion of } \\
\text { wellbeing through the }\end{array}$ & 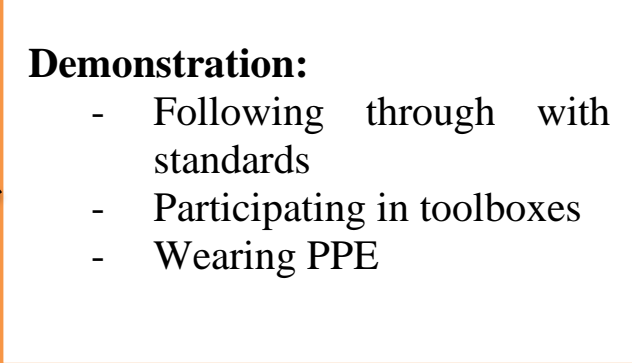 \\
\hline $\begin{array}{l}\text { Vision: } \\
\quad \text { - } \quad \text { Project goals and vision } \\
\text { - } \\
\text { - } \quad \text { Mafety expectations } \\
\text { Mapping the desired state }\end{array}$ & discipline & $\begin{array}{l}\text { Promotion: } \\
\text { - Influencing others through } \\
\text { goals } \\
\text { - Outlining a broader vision } \\
\text { - Discussing safety in a } \\
\text { positive light }\end{array}$ \\
\hline
\end{tabular}

Figure 1: Integral Components to the Definition of Safety Leadership (Daniel (2015) 


\section{Conclusion:}

Safety leadership has its unique variables established by the operating environment that it exists within and therefore differs from other leadership models. The implication of such variables, allows a more viable discourse into the area of safety leadership which may minimise confusion and lack of clarity around the topic. The separation of how safety leadership differs from other disciplines is one of the key contributing factors. Future safety leadership programs can be crossmapped for validity and linked to behaviours emanating from safety leadership definition and help reduce work related incidents. The detailed definition of safety leadership may serve as a foundation for other industries such as mining, manufacturing or petrochemicals. The operating environment across the industries may slightly differ, although the safety leadership factors detailed in the definitions may still ring true.

\section{Reference:}

Biggs, H.C., Dingsdag, D.P. and Roos, C.R., 2008. A practical guide to safety leadership: Implementing a construction safety competency framework. Cooperative Research Centre for Construction Industry, Brisbane: IconNet.

Clarke, S., 2013. Safety leadership: A meta-analytic review of transformational and transactional leadership styles as antecedents of safety behaviours. Journal of Occupational and Organisational Psychology, 86(1), pp.22-49

Cooper, D., 2015. Effective safety leadership. Professional Safety, 60(2), pp.49-53. Durban, A.J., Dalglish, C. and Miller, P. 2006. Leadership. Milton: John Wiley and Sons Australia.

Hashim, I.N. and Chileshe, N., 2012. Major challenges in managing multilpe project environment (MPE) in Australia's construction industry. Journal of Engineering, Design and Technology, 10(1), pp.72-92.

Long, D.G., 2013. Delivering High Performance: The Third Generation Organisation. Farnham: Gower Publishing Limited.

Lu, C.S. and Yang C.S., 2010. Safety leadership and safety behavior in container terminal operations. Safety Science, 48(1), pp.123-34.

Luke Daniel 2015. Safety Leadership Defined within the Australian Construction Industry. Construction Economics and Building, 15(4), 1-15

Mullen, J.E. and Kelloway, E.K., 2009. Safety leadership: A longitudinal study of the effects of transformational leadership on safety outcomes. Journal of Occupational and Organisational Psychology, 82(2), pp.253-72. 
O'Dea, A. and Flin, R., 2001. Site managers and safety leadership in the offshore oil and gas industry. Safety Science, 37(1), pp.39-57

Read, B.R., Zartl-Klik, A., Veir, C., Samhaber, R. and Zepic, H., 2010. Safety Leadership that engages the workforce to create sustainable HSE performance. SPE International Conference on Health, Safety and Environment in Oil and Gas Exploration and Production. Rio de Janeiro, Brazil, pp.1-18.

Wu, T.C., Chen, C.H. and Li, C.C., 2008. A correlation among safety leadership, safety climate and safety performance. Journal of Loss Prevention in the Process Industries, 21(3), pp.307-18.

Zanko, M. and Dawson, P., 2012. Occupational health and safety management in organisations: A review. International Journal of Management Reviews, 14(3), pp.328-44. 